\title{
Profile of our distinguished retiring Editor, Mr Phillip Harris
}

Phillip Harris was born in Edinburgh on 28 March 1922. He was educated at the Royal High School of Edinburgh and graduated from the School of Medicine of the Scottish Royal College and Edinburgh University in 1944. He obtained the FRCS(Ed) in October 1948, MRCP(Ed) in 1954, $\mathrm{FRCP}(\mathrm{Ed})$ in 1959 and FRCS(Glas) in May 1964. In 1967 he was elected a Fellow of the Royal Society of Edinburgh.

Hard work, thoroughness and exactitude were second nature to him. At the School of Medicine he was medallist in Anatomy, Physiology, Physics, Materia Medica, Therapeutics, Midwifery, Gynaecology, Medicine and Surgery.

Between 1942 and 1944 he was an undergraduate demonstrator in Anatomy and obtained two silver medals. From 1945 to 1948 he was a Captain in the Royal Army Medical Corps (RAMC).

$\mathrm{He}$ had the privilege and opportunity of working with Professor Norman Dott, Sir Hugh Cairns, Sir Charles Symonds, Professor Sir Walter Mercer, Professor Ritchie Russell and other distinguished figures in British Neurology and Neurosurgery. Mentors out with the UK included Dr Wilder Penfield, Dr Earl Walker, Dr Frank Mayfield, Drs French and Magoun in UCLA and in Hong Kong Professor Hodgson and Dr Fang.

Phillip Harris was appointed Consultant Neurosurgeon in Edinburgh in 1955 and subsequently Senior Lecturer in Neurosurgery at the University of Edinburgh, posts he had held with great distinction.

He first met Sir Ludwig Guttmann in Stoke Mandeville Hospital in 1945 and subsequently became a founder member of the International Medical Society of Paraplegia. He is also a founder member of several other distinguished societies including the British Cervical Spine Society and the Scottish Association of Neurological Sciences.

As an experienced Neurosurgeon, Phillip Harris is a world authority on lesions of the spinal cord and has conducted both clinical and experimental research on cervical spine injuries, cervical intervertebral disc disease and facet joint disorders. He also helped to develop new surgical lasers. He conducted extensive experimental animal researches and clinical studies on epilepsy and has designed a number of new surgical instruments and appliances and several new neurosurgical operative procedures.

To date, Phillip Harris, has some 100 publications to his name and is also the author and co-author of several books and chapters in books and member of the editorial boards of medical journals. He has given many medical presentations in most countries of the five continents. From a very early stage in his career

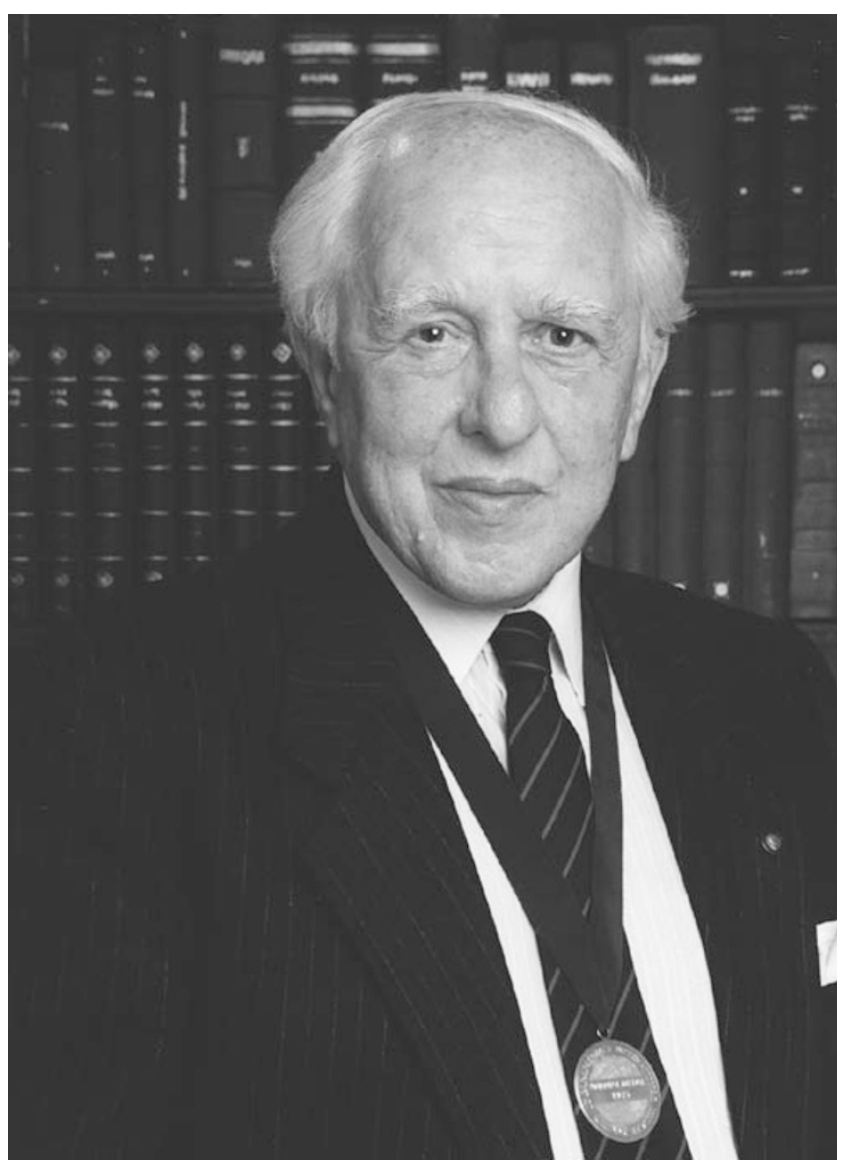

he took an active interest in teaching and training. $\mathrm{He}$ has also been an examiner for the Royal College of Surgeons and the Royal College of Physicians of Edinburgh. Phillip Harris is past Chairman of the UK Government Board (PLAB) to carry out examinations for the assessment of medical professional knowledge and language abilities of overseas qualified doctors wishing to take up hospital appointments in the UK. Most of his students have been appointed Consultant Neurosurgeons in many countries of the five continents including the USA, Canada, Australia, South America and the UK. His international activities include numerous visiting Professorships; Senior Delegate of the Society of British Neurosurgeons to the World Federation of Neurosurgical Societies (WFNS) for 16 years, Vice Chairman of the Neurotraumatology Committee of the WFNS and many other advisory roles which space does not permit me to enumerate. He has advanced and helped with the development of many Spinal Injuries Centres in different parts of the world. 
In 1970 he was offered a Chair of Professor of Neurosurgery at Harvard University but his national and international involvement and commitments and his strong roots in Scotland caused him to decline this tempting and prestigious offer. Some of his trainees have gained Chairs and have become influential in the field of neurosurgery. Despite the pressure of work on his time, Phillip never forgot the importance and the role of the members of the various paramedical professions. He developed an annual course for postgraduate nurses in Neurology and Neurosurgery and gave lectures to physiotherapists and occupational therapists and was also Chairman of the School of Occupational Therapy.

Phillip Harris has been involved with the journal of Paraplegia since its inception in 1963. He was Assistant Editor to Sir Ludwig Guttmann between 1963 and 1980 when the journal was published on a quarterly basis. Plans to publish six issues of the journal a year were already in motion. Upon the death of Sir Ludwig Guttmann in 1980, Phillip Harris was elected Editor of Paraplegia. He implemented these plans and started presiding over a systematic transformation of the journal both in content and in appearance. This he has achieved without changing the philosophy or the aims of the journal which are, 'To provide an international forum for an easy interchange of ideas for all those responsible for the welfare of our paralysed fellow men as well as to promote further elucidation of the many and varied aspects of this problem'. With an open, though critical mind, he accepted manuscripts at the fore front of clinical medicine and science, ensuring that no clinicians or scientist was excluded because of their geographical base. He has shown particular skill in appointing members to his Editorial Board, whom he invited from most fields of medicine, surgery and clinical sciences. This was no mean task in itself but he also managed to attract the best in each field. In 1985 Phillip Harris was awarded the Medal of the Society and, as $\mathrm{Mr}$ James Cosbie Ross, distinguished Neurologist and an Assistant Editor of the journal said, 'It was universally felt that no one deserved it more'.

Like his predecessor, Mr Harris has proved to be a very demanding Editor, hence his ability to improve the standard of the journal year after ear. I am sure that many members of the Editorial Board, including myself, will have received 'phone calls from Phillip
Harris during the evening or at the weekend to discuss a manuscript or some other Editorial business. With his gentle persuasion and sense of humour however he has managed to retain the required members of the Editorial Board.

With is dedication at the helm, he has increased the issues of the journal to nine in 1990 and 2 years later, to 12 issues per year. He revised the cover of the journal twice, first in 1992 and again in 1995. I am sure that all readers will agree that the new cover and typography are very pleasing.

A tremendous negotiator, Phillip Harris has managed to generate interest from Stockton, our new publisher, and has ensured a smooth transition of the journal during the change of publisher in 1991.

Phillip Harris' skills and interests extend beyond the field of medicine, for example, he is Founder, Chairman and now Honorary President of the Scottish Sports Association for the Disabled. Involvements with organisations for the care of the physically disabled people including being a trustee and director of the Margaret Blackwood Housing Association. A keen golfer, Phillip also enjoys the opera and the arts and has a particular interest in Rembrandt. In 1992 he became President of the Rotary Club of Edinburgh.

Phillip Harris shares the credit of his achievements with Sheelagh, his devoted wife for 48 years. Frances, their daughter is a respected physiotherapist in London. Harvey, their son is a successful Solicitor in Glasgow. They have been blessed with a grand daughter, Abigail, who is $2 \frac{1}{2}$ years old and will be proud of her grandfather for decades to come.

The reader will agree with me that we have been very fortunate to have had Phillip help create and edit our prestigious journal over the last 34 years. For a man who believes that 'Work is Fun' we wish to thank him for all his hard work as Assistant Editor and Editor of Paraplegia and Spinal Cord. We also wish him and Sheelagh a great deal of 'Fun' for many years to come.

It is with great pride that Phillip Harris, the readers of Spinal Cord, the members of the Editorial Board and I welcome our new Editor, Dr Lee Illis, who is an equally energetic and formidable figure in the field of Neurosciences.

WS El-Masry FRCS(Ed) Assistant Editor 